\title{
Salário Mínimo, “Efeito-Farol” e Pobreza
}

\author{
Minimum Wage, "Lighthouse Effect" and Poverty
}

\author{
MARCELO NERI* \\ GUSTAVO GONZAGA** \\ JOSÉ MARCIO CAMARGO***
}

\begin{abstract}
RESUMO: Este artigo avalia a efetividade da política de salário mínimo em vários segmentos do mercado de trabalho brasileiro. Nossa técnica básica é quantificar as soluções de canto impostas pelo salário mínimo. Esses pontos são posteriormente utilizados como um mecanismo de focalização na simulação dos limites superiores dos efeitos do salário mínimo nas medidas de pobreza. Destacamos a importância de dois efeitos incomuns do salário mínimo: i) A alta porcentagem de funcionários informais que recebem exatamente um salário mínimo, isso aumenta os efeitos do mínimo sobre a pobreza; e ii) o uso do salário mínimo como numerário na determinação de salários, em particular no setor formal.

PALAVRAS-CHAVE: Salário mínimo; desigualdade; pobreza.
\end{abstract}

ABSTRACT: This paper evaluates the effectiveness of the minimum wage policy in various segments of Brazilian labor markets. Our basic technique is to quantify corner solutions imposed by the minimum wage. These points are later used as a focalization mechanism in the simulation of upper bounds of the effects of the minimum wage on poverty measures. We highlight the importance of two unusual effects of the minimum wage, i) The high percentage of informal employees receiving exactly one minimum wage, this enhances the effects of the minimum on poverty, and ii) The use of the minimum wage as a numeraire in wage determination, in particular within the formal sector.

KEYWORDS: Minimum wage; inequality; poverty.

JEL Classification: J31; J38.

\footnotetext{
* Professor da Escola Brasileira de Economia e Finanças da Fundação Getúlio Vargas - EPGE/FGV, Rio de Janeiro/RJ, Brasil. E-mail: Marcelo.nery@fgv.br. Orcid: https://orcid.org/0000-0002-5911-6951.

** Pontifícia Universidade Católica do Rio de Janeiro - PUC-Rio, Rio de Janeiro/RJ, Brasil. E-mail: gonzaga@econ.puc-rio.br. https://orcid.org/0000-0001-9358-3177..

*** Pontifícia Universidade Católica do Rio de Janeiro - PUC-Rio, Rio de Janeiro/RJ, Brasil.E-mail: jcamargo@econ.puc-rio.br.
} 


\section{INTRODUÇÃO}

O objetivo final deste artigo é subsidiar a formulação da política de salário mínimo no Brasil. Inicialmente, avaliamos a efetividade da política de salário mínimo nacional para as diversas formas de inserção ocupacional do mercado de trabalho brasileiro ${ }^{1} \mathrm{~A}$ nossa técnica consiste em mapear pontos de pressão/soluções de canto produzidas pela política de salário mínimo.

A medida do grau de efetividade do salário mínimo aqui utilizada nos permite distinguir os diversos efeitos do mínimo no mercado de trabalho brasileiro. Além do tradicional efeito sobre os empregados formais (funcionários públicos e empregados com carteira assinada) que recebem exatamente um salário mínimo, destacamos dois efeitos até certo ponto inesperados produzidos pelo mínimo: i) a alta porcentagem de empregados sem carteira assinada que têm seus salários fixados de acordo com o valor do mínimo²; e ii) o grande número de trabalhadores que utilizam o salário mínimo como numerário, em particular, entre os empregados formais (efeito-numerário).

O efeito-numerário é captado através de níveis de salários equivalentes a de terminados múltiplos do mínimo (i.e., 1 s.m., 2 s.m., 3 s.m., 1.5 s.m. e 2.5 s.m.). Neste último aspecto a metodologia consiste numa aplicação em termos de níveis de renda da metodologia proposta em Neri (1997) para variações de salário.

Estes pontos de pressão produzidos pela política de salário mínimo captados individualmente são utilizados, posteriormente, como mecanismo de focalização na simulação de limites superiores de efeitos de reajustes do salário mínimo sobre a renda familiar per capita e, em particular, sobre medidas de pobreza no Brasil. Neste aspecto, o exercício é semelhante em espírito àquele empreendido em Gramlich (1976).

\section{EFETIVIDADE DO SALÁRIO MÍNIMO NOS DIVERSOS SEGMENTOS DO MERCADO DE TRABALHO}

O objetivo desta seção é mapear o grau de efetividade do salário para as diversas formas de inserção ocupacional do mercado de trabalho brasileiro. A medi-

\footnotetext{
${ }^{1}$ As categorias de inserção ocupacional analisadas nesse artigo são as seguintes: empregados formais (funcionários públicos e trabalhadores com carteira assinada), empregados informais (sem carteira assinada), e trabalhadores por conta própria (que incluem autônomos regulamentados e nãoregulamentados). Tal classificação nos permite concentramo-nos no ponto principal do artigo que é avaliar a efetividade do mínimo entre aqueles que formal e legalmente deveriam ser afetados pela legislação - os empregados formais que recebem salários equivalentes ao mínimo - e entre os trabalhadores nas de mais formas de inserção ocupacional.

${ }^{2}$ A princípio o segmento informal do mercado de trabalho estaria fora do alcance dos efeitos coercitivos da regulação incidente sobre os salários. No entanto, alguns argumentam que o salário mínimo pode ser usado como balizador das rendas do trabalho nos segmentos informais da economia, fenômeno denominado "efeito-farol".
} 
da de efetividade inicialmente proposta é a porcentagem de trabalhadores que recebem remunerações idênticas ao valor do salário mínimo.

\section{Metodologia}

O efeito mais característico de uma política de salário mínimo sobre os salários é o de deslocar a massa da distribuição de salários com níveis inferiores aos do mínimo, concentrando-a no valor exato assumido pelo mínimo. A ideia é que, caso não houvesse a política de salário mínimo, observaríamos uma distribuição contínua na qual cada ponto no domínio da distribuição teria uma probabilidade nula de ser observado. A política de salário mínimo discretiza parte desta distribuição, concentrando massa positiva no valor assumido pelo mínimo.

Neste sentido, o cálculo de medidas de avaliação da efetividade do mínimo sobre a distribuição de salários deveria se basear no número de indivíduos recebendo exatamente um salário mínimo, e não na comparação de médias dos salários com o valor do mínimo, ou em estatísticas como a proporção de indivíduos que recebem abaixo do mínimo.

A ideia intuitiva por trás deste indicador é que, como a proporção de trabalhadores em qualquer ponto da distribuição deveria ser nula, o efeito do mínimo é o de deslocar pessoas abaixo do mínimo exatamente para o valor do mínimo. Portanto, a proporção de trabalhadores com salários idênticos ao mínimo corresponderia a uma medida da parcela dos ocupados afetada pela existência do piso nacional de salários. ${ }^{3}$ Em outras palavras, estamos avaliando o tamanho da solução de canto imposta pelo salário mínimo à distribuição dos salários no Brasil.

A base de dados utilizada é a PNAD (Pesquisa Nacional de Amostra por Domicílio), realizada pelo IBGE em setembro de 1996. A sistemática de utilizar a massa da distribuição com valores exatamente iguais ao salário mínimo é especialmente relevante para este período (entre maio de 1996 e abril de 1997), quando o salário mínimo assumiu o valor de $\mathrm{R} \$ 112,00$, um valor “quebrado". Isto não ocorreu, por exemplo, durante o período entre maio de 1995 e abril de 1996, quando o valor de R \$100,00 assumido pelo mínimo não nos permite avaliar com clareza se a concentração de salários iguais a $\mathrm{R} \$ 100,00$ refletia a influência direta do mínimo ou outras razões, como um simples arredondamento. ${ }^{4}$ Neste sentido, a PNAD/96 constitui um laboratório privilegiado para a aferição da efetividade da política de salário mínimo no Brasil, uma vez que a única referência óbvia associada ao valor de $\mathrm{R} \$ 112,00$ é o fato de que este era o valor do salário mínimo na época.

\footnotetext{
${ }^{3}$ Card e Krueger (1995) demonstram que a legislação do salário mínimo afeta também valores acima próximos ao mínimo.

${ }^{4}$ Paulo Paiva comparou o problema gerado por esta metodologia quando o salário mínimo corresponde a $\mathrm{R} \$ 100,00$ com os problemas enfrentados pelos demógrafos devido ao hábito dos entrevistados de pesquisas domiciliares de arredondar o valor das suas idades em torno de múltiplos de 5 anos.
} 


\section{Avaliação Empírica}

Conforme mencionado acima, a técnica inicialmente utilizada para medir o grau de efetividade do salário mínimo constitui na aferição da proporção dos trabalha dores que recebem exatamente um salário mínimo no Brasil.

Através da Tabela 1 a seguir, podemos comparar o grau de efetividade do salário mínimo para o total de trabalhadores e para diversos segmentos do mercado de trabalho brasileiro. Conforme já mencionado, as categorias de inserção ocupacional analisadas neste artigo são as seguintes: empregados formais (funcionários públicos e trabalhadores com carteira assinada), empregados informais (sem carteira assinada), e trabalhadores por conta própria. A seguir, analisamos separada mente os resultados para cada um desses segmentos.

\section{Empregados Formais e Múltiplos do Mínimo}

Iniciamos a análise da efetividade do salário mínimo olhando para o conjunto total de trabalhadores brasileiros e para os empregados formais. ${ }^{5}$ A segunda coluna da Tabela 1 revela que, em setembro de 1996, 9\% dos trabalhadores brasileiros recebiam exatamente um salário mínimo $(\mathrm{R} \$ 112,00)$.

Passando agora ao segmento de empregados formais, o qual está sujeito às imposições da legislação trabalhista. De acordo com a PNAD/96, 8\% dos trabalhadores com carteira assinada (cerca de um milhão e meio de indivíduos) percebiam salários idênticos ao salário mínimo, ou seja, exatamente $\mathrm{R} \$ 112,00$, em setembro de 1996.

Tabela 1

Proporção de Salários Idênticos ao Mínimo e múltiplos do Mínimo (Brasil - setembro de 1996)

\begin{tabular}{cccccc}
\hline Múltiplos & Todos & Setor Público & Com Carteira & Sem Carteira & Conta Própria \\
\hline 1 & 9 & 8 & 8 & 15 & 3 \\
2 & 2 & 1 & 3 & 2 & 2 \\
3 & 0 & 1 & 1 & 1 & 1 \\
\hline Abaixo* $^{*}$ & 15 & 8 & 2 & 30 & 24 \\
0,5 ou $1,5^{*}$ & 1 & 0 & 2 & 2 & 2 \\
\hline
\end{tabular}

* do Mínimo $(\mathrm{R} \$ 112,00)$

Fonte: PNAD 1996

Uma análise visual da distribuição de salários dos empregados formais revela também a existência de pontos de acumulação de massa em outros múltiplos do salário mínimo. Conforme Neri (1997) argumenta, o salário mínimo tem sido amplamente difundido como numerário ou unidade de conta no processo de fixação de salários no Brasil. Ou seja, é comum os trabalhadores terem suas rendas

\footnotetext{
${ }^{5}$ Este agregado corresponde ao total de ocupados remunerados, aí incluindo conta-próprias e empregadores.
} 
fixadas em termos de múltiplos de um salário mínimo legal. Este efeito-numerário constitui o primeiro efeito pouco usual do salário mínimo aqui considerado. É importante destacar que a Constituição de 1988 pró́be a prática de indexação de salários ao mínimo. Neste sentido, o uso do mínimo como numerário no setor formal constitui uma prática ilegal.

De acordo com a PNAD/96, cerca de $14 \%$ do conjunto total de trabalhadores com carteira assinada ganhava exatamente determinados múltiplos do salário mínimo vigente na época (1 s.m. [R \$112,00], 2 s.m. [R $\$ 224,00], 3$ s.m. [R \$336,00), $0,5$ s.m. $[\mathrm{R} \$ 56,00)$ e 1.5 s.m. [R $\$ 168,00]) .{ }^{6} \mathrm{O}$ efeito-numerário, portanto, é responsável pela determinação de $6 \%$ dos salários dos trabalhadores com carteira assinada.

No conjunto dos funcionários públicos das três esferas de governo, a proporção de indivíduos com salários idênticos ao mínimo é similar àquela observada entre os trabalhadores com carteira assinada, $8 \%$. No entanto, o uso do salário mínimo como numerário (indexador) se revela uma prática menos proeminente entre os funcionários públicos: apenas $2 \%$ dos funcionários públicos recebiam os múltiplos diferentes do piso legal contra $6 \%$ dos empregados com carteira assinada.

\section{Empregados informais e trabalhadores por conta própria}

A Tabela 1 mostra que a importância relativa das soluções de canto causadas pelo salário mínimo entre os trabalhadores sem carteira de trabalho é mais forte do que aquelas operantes entre os empregados formais. Em outras palavras, de forma até certo ponto surpreendente, a legislação do salário mínimo é mais efetiva (binding) no segmento assalariado ilegal do mercado de trabalho brasileiro do que no segmento assalariado legal. Os dados da PNAD/96 mostram que 20\% dos empregados sem carteira assinada recebiam algum dos múltiplos do salário mínimo aqui considerados, número bem superior aos $14 \%$ observados entre os empregados com carteira e aos $10 \%$ observados entre os funcionários públicos.

Os trabalhadores, por conta própria, por sua vez apresentam uma proporção de rendimentos exatamente iguais ao mínimo e aos múltiplos do mínimo analisados de $3 \%$ e $8 \%$. Este nível se situa em patamares bem inferiores em relação àqueles observados para o conjunto de assalariados, principalmente os empregados sem carteira ${ }^{7}$. A distinção entre os segmentos sem carteira e com carteira é ainda mais pronunciada quando comparamos a proporção de empregados que ganhavam ape-

\footnotetext{
${ }^{6}$ De acordo com dados da PME 97-98, o uso do salário mínimo como numerário nas regiões metropolitanas seria ainda mais acentuado pois $18 \%$ dos empregados formais recebem múltiplos do salário mínimo. Neri (1997) propõe a unificação destes efeitos calculando a partir de dados longitudinais a proporção de trabalhadores cujos reajustes coincidem com os do mínimo

${ }^{7}$ Souza e Baltar (1983), que cunharam a expressão "efeito-farol” conferem mais ênfase aos contapróprias e pequenos empregadores do que aos trabalhadores sem carteira de trabalho. Neri (1997) demonstra que a operação dos efeitos do salário mínimo sobre os segmentos conta-própria e de empregados sem carteira no começo da década de 80 era reduzida.
} 
nas um salário mínimo: $15 \%$ para os empregados informais contra $8 \%$ para os empregados formais. ${ }^{8}$

Por outro lado, uma ordenação diversa é observada com relação à importância na determinação das remunerações dos múltiplos diferentes de um salário mínimo: $5 \%$ dos sem carteira contra $6 \%$ dos com carteira. Em outras palavras, o efeito numerário (ou seja, a prática informal de utilizar o salário mínimo apenas como indexador) é mais forte em termos relativos entre os assalariados formais. Este resultado pode ser parcialmente creditado à maior renda dos assalariados formais, o que explica a maior importância dos múltiplos de mínimo acima de 1 salário mínimo neste segmento.

\section{Chefes de Domicílio}

A análise de efetividade do salário mínimo entre os principais provedores de renda dos domicílios é de fundamental importância para aferirmos o impacto dos reajustes do salário mínimo sobre a pobreza. No universo de chefes de domicílio empregados no setor formal, a proporção de indivíduos que têm remunerações iguais ao salário mínimo cai para 5\%, com base nos dados da PNAD/96.

\section{Padronizando a Jornada de Trabalho}

Uma última questão relativa ao cálculo da efetividade do mínimo se refere à padronização da jornada de trabalho. A tabela 1 b replica a tabela 1 impondo uma padronização da jornada de trabalho em 40 horas semanais. A comparação das duas tabelas não revela diferenças significativas do grau de efetividade do mínimo entre os diversos segmentos do mercado de trabalho brasileiro. O grau total de efetividade fica na faixa de um a dois pontos percentuais daquele encontrado sem a padronização das horas trabalhadas.

Tabela 1b: Proporção de Salários Idênticos ao Mínimo e Múltiplos do Mínimo (Brasil - setembro de 1996) Padronizando a Jornada de Trabalho em 40 horas

\begin{tabular}{cccccc}
\hline Múltiplos & Todos & Setor Público & Com carteira & Sem carteira & Conta própria \\
\hline 1 & 7 & 6 & 7 & 14 & 2 \\
2 & 2 & 1 & 3 & 2 & 1 \\
3 & 1 & 1 & 2 & 0 & 1 \\
\hline Abaixo* $^{*}$ & 13 & 3 & 1 & 27 & 26 \\
0,5 ou $1,5^{*}$ & 1 & 0 & 1 & 2 & 0 \\
\hline
\end{tabular}

*do Mínimo $(\mathrm{R} \$ 112,00)$

Fonte: PNAD 1996

\footnotetext{
${ }^{8}$ Esta relação entre a proporção de afetados nos segmentos de assalariados formais e informais é semelhante quando usamos como fonte de dados a Pesquisa Mensal de Emprego (PME) de fevereiro de 1998.
} 
A diferença mais significativa das duas tabelas se refere à menor porcentagem da proporção de trabalhadores com rendimentos padronizados por jornada de trabalho em quase todos segmentos analisados (a exceção são os trabalhadores por conta própria). Em particular, a proporção de funcionários públicos que não cumprem o requisito da legislação do salário mínimo quando incorporamos a padronização de horas cai de $8 \%$ para $3 \%$.

\section{SIMULAÇÕES DOS EFEITOS DO SALÁRIO MÍNIMO SOBRE A POBREZA}

O objetivo desta seção é avaliar o impacto de reajustes do salário mínimo sobre os indicadores de pobreza no Brasil.

\section{Metodologia}

O exercício básico desta seção consiste em simular o efeito de reajustes reais do salário mínimo sobre a renda dos indivíduos de diferentes segmentos do mercado de trabalho para os quais a política de salário mínimo é efetiva (binding). A identificação dos indivíduos afetados pelo mínimo segue a metodologia desenvolvida na seção anterior. O exercício consiste em aplicar um determinado reajuste real do salário mínimo aos salários em que há coincidência entre rendimentos individuais e determinados múltiplos do mínimo (i.e., 1 s.m., 2 s.m., 3 s.m., 1.5 s.m. e 2.5 s.m.) É importante destacar que o exercício consiste em reajustar a renda do trabalho dos indivíduos afetados pelo mínimo sem considerar outros possíveis efeitos colaterais do reajuste do mínimo. É óbvio que, além dos impactos sobre o nível de rendimento dos empregados, aumentos do salário mínimo podem exercer impactos adversos sobre o nível e a qualidade do emprego. No entanto, ainda não existem estudos no Brasil que apresentem medidas da elasticidade emprego-salário para os trabalhadores que recebem valores próximos ao salário mínimo. ${ }^{9}$

$\mathrm{Na}$ literatura internacional, há um concorrido debate a respeito da observação de efeitos negativos de aumentos do salário mínimo sobre o nível de emprego. Card e Krueger (1995) apresentam evidências consistentes de efeitos próximos de zero (e até mesmo positivos) do salário mínimo sobre o emprego.

No presente estudo, estamos supondo arbitrariamente que a elasticidade em prego-salário para os trabalhadores que recebem valores próximos ao salário mí-

\footnotetext{
${ }^{9}$ Neri (1997), utilizando o reajuste de $43 \%$ concedido em maio de 1995 , demonstra que as probabilidades de grupos de empregados formais afetados pelo mínimo transitarem em direção ao desemprego e à informalidade são superiores àquelas encontradas para os grupos não afetados. Apesar disto, como Amadeo e Neri (1998) demonstram, maio de 1995 representa uma inflexão das séries de pobreza brasileira
} 
nimo é nula. As simulações aqui apresentadas podem ser vistas, portanto, como limites superiores dos efeitos exercidos pelo salário mínimo sobre a pobreza. ${ }^{10}$

No caso dos empregados formais, aplica-se um reajuste real também para os trabalhadores que recebiam salários entre os valores do antigo e do novo mínimo, de forma que sejam todos deslocados para o valor do novo mínimo ("efeito-arrasto"). Aplicamos o "efeito-arrasto" apenas aos empregados formais que ganham próximo de um mínimo pois este efeito advém exclusivamente da operação da legislação, não tendo relação com o efeito-numerário discutido acima.

No passo seguinte, agregam-se no nível familiar as rendas do trabalho auferidas individualmente e calculam-se indicadores de pobreza. Este processo é repetido de maneira sequencial de forma a ampliar paulatinamente o escopo da atuação da política de reajuste do salário mínimo. Começamos mensurando os efeitos aliviadores de pobreza supondo que o mínimo afeta unicamente os empregados formais que ganham valores entre o salário mínimo antigo e o novo. Posteriormente, incorporamos outros efeitos do mínimo: aqueles atuantes sobre os trabalhadores sem carteira de trabalho e o efeito-numerário sobre os empregados formais.

Os impactos do salário mínimo são percebidos individualmente, enquanto os indicadores de pobreza são levantados tendo-se em conta todas as fontes de renda do trabalho auferidas em todos os membros dos domicílios. A fim de tecer considerações diretas a respeito desse efeito sobre os indicadores sociais que levem em conta o processo de agregação das rendas do trabalho dentro dos domicílios, apresentamos uma série de simulações. Essas simulações apresentam os efeitos cumulativos sobre a proporção dos pobres medida em termos de renda domiciliar per capita do trabalho.

\section{Trabalhadores que recebem um salário mínimo}

As sequências de simulações apresentadas no Gráfico 1 estudam os efeitos de um reajuste real de $42.86 \%$ concedido ao salário mínimo (o mesmo reajuste concedido em maio de 1995) sobre a proporção de pobres (P0), tomando como base uma linha de pobreza nacional de $\mathrm{R} \$ 43,00^{11}$ • O Gráfico 1 apresenta os efeitos cumulativos do reajuste do mínimo sobre o nível do indicador de pobreza. A barra $\mathrm{N}$ do Gráfico 1 apresenta a proporção de pobres avaliada com a linha de pobreza de $\mathrm{R} \$ 43,00$. As barras seguintes apresentam o valor desta medida de pobreza quando são incorporados, cumulativamente, os efeitos de um reajuste do salário

\footnotetext{
${ }^{10}$ Este exercício é similar em espírito àqueles encontrados em Gramlich (1976). As diferenças se referem à incorporação de outros efeitos do mínimo nas simulações, ao fato dos mecanismos de focalização aqui se basearem explicitamente na mensuração da efetividade do mínimo através dos pontos de pressão coincidentes com o mínimo e a não incorporação de uma negativa declividade da demanda por trabalho nas nossas simulações.

${ }^{11}$ Este valor foi escolhido para manter a comparabilidade com os efeitos aliviadores de pobreza de outras políticas discutidas em Barros (1998), conforme discutido nas conclusões do artigo. Neri (1997) apresenta simulações análogas à desta seção usando outras linhas de pobreza e outros indicadores de pobreza.
} 
mínimo em diversos segmentos do mercado de trabalho. A segunda barra, 1C, revela que ao incorporarmos o reajuste de $43 \%$ aos trabalhadores com carteira assinada de cada domicílio que recebiam um salário de exatamente $R \$ 112,00$, essa proporção seria de $29.6 \%$. Os empregados formais que percebiam salários entre $\mathrm{R} \$ 112,00$ e o novo mínimo assumido de $\mathrm{R} \$ 160,00$ receberam reajustes em cascata sendo todos deslocados para o valor do novo mínimo ("efeito-arrasto").

A variação percentual do nível de pobreza como resultado do reajuste de salários dos afetados pela legislação do salário mínimo no sentido tradicional (os trabalhadores com carteira assinada que recebiam um mínimo ou entre o antigo e o novo mínimo) seria de $1,87 \%$. Ao incorporarmos os efeitos do mínimo sobre os trabalhadores sem carteira que ganhavam exatamente um salário mínimo na análise (barra 1CS) a queda cumulativa de pobreza aumenta para $3.53 \%$. No caso dos trabalhadores sem carteira assinada, não incorporamos o "efeito-arrasto", mencionado acima, pois este atua apenas devido à exigência da legislação.

\section{Gráfico 1: Simulaçõe s sobre Im pacto de Reajustes Reais ao Salário Mínimo Reajuste de 43\% - Renda do Trabalho - Brasil Proporção de Pobres - R\$ 43 Nível de Pobreza}

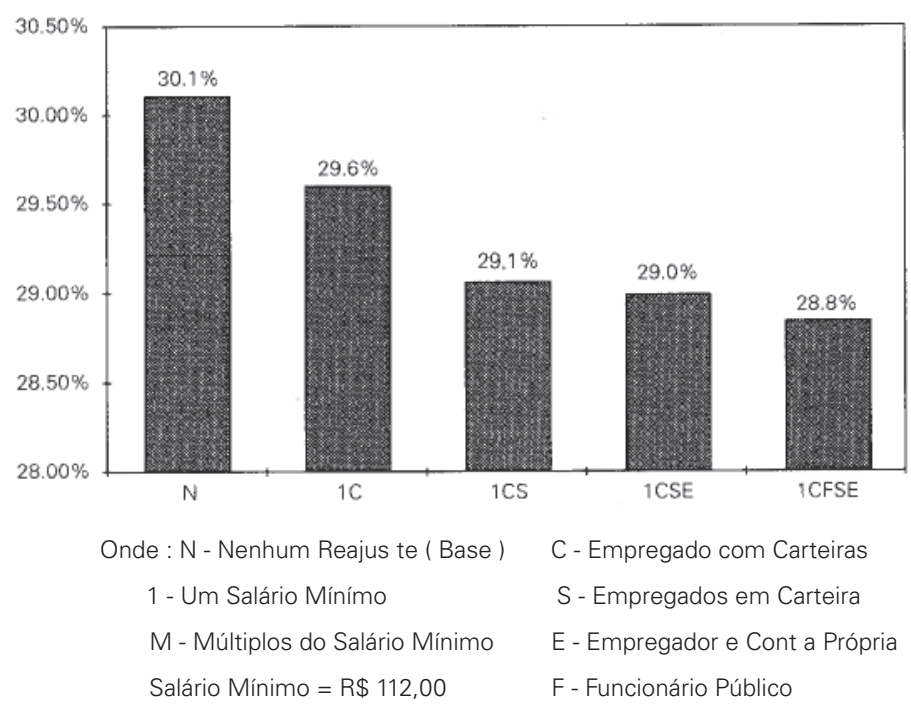

Conforme esperado, a incorporação de conta próprias e empregadores que ganhavam exatamente um mínimo afeta pouco a proporção de pobres observada: o efeito cumulativo de queda de pobreza proporcionado pelo reajuste do mínimo aumenta de $3.53 \%$ para $3.92 \%$. Finalmente, a incorporação de funcionários públicos que ganhavam exatamente o mínimo produz efeitos semelhantes sobre o nível de pobreza que atinge a queda cumulativa de $4.59 \%$. Neste último passo, é considerada na simulação a operação do "efeito-arrasto". 


\section{Trabalhadores que recebem múltiplos do salário mínimo}

No Gráfico 2, é apresentado o resultado das simulações que seguem uma sequência alternativa àquela do Gráfico 1. Estas simulações partem das mesmas hipóteses básicas da sequência anterior (i.e., Proporção dos Pobres (P0), linha de pobreza $\mathrm{R} \$ 43$ e reajuste do salário mínimo correspondente a $42.86 \%$ ). As principais modificações introduzidas se referem à ordem em que os diversos efeitos são considerados e à incorporação de outro efeito do salário mínimo, o seu uso como indexador (o efeito-numerário, discutido na seção 2). Este efeito é considerado ao incorporarmos na simulação aqueles trabalhadores cujas rendas coincidem com alguns múltiplos do salário mínimo de $\mathrm{R} \$ 112,00$ (0.5, 1, 1.5, 2 e 3 salários mínimos). Como o atrelamento a múltiplos do salário mínimo diferentes de um salário mínimo não constitui parte da legislação salarial brasileira, consideramos a operação do " efeito-arrasto " somente para os trabalhadores com carteira que ganham entre 1 salário mínimo antigo e o novo.

\section{Gráfico 2: Simulações sobre Impacto de Reajustes Reais ao Salário Mínimo \\ Reajuste de 43\% - Renda do Trabalho - Brasil \\ Proporção de Pobres - R\$ 43 Nível de Pobreza}

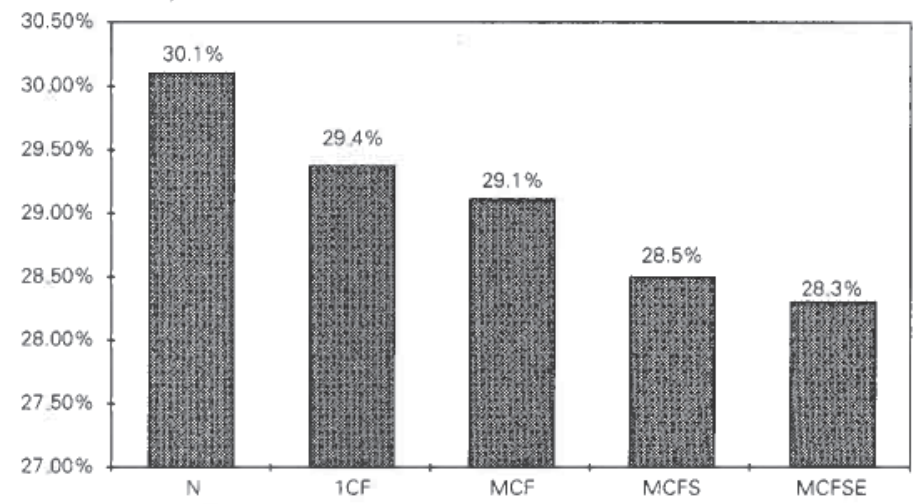

Como na sequência anterior, a primeira etapa, N, do Gráfico 2 corresponde ao nível do indicador de pobreza sem levar em conta os efeitos do reajuste conferido ao salário mínimo. A segunda etapa, $1 \mathrm{CF}$, capta a aplicação do reajuste do salário mínimo de $43 \%$, estritamente conforme estipulado na legislação. Isto é, incorporamos apenas os empregados formais (empregados com carteira de trabalho e funcionários públicos), incluindo a operação do "efeito-arrasto". Neste estágio, a pobreza cai de $30.1 \%$ para $29.4 \%$, uma queda de $2.53 \%$.

$\mathrm{O}$ estágio seguinte, $\mathrm{MCF}$, incorpora à etapa anterior o efeito indexador do salário mínimo aos empregados formais, isto é, aqueles trabalhadores que ganham múltiplos de mínimo diferentes de um salário mínimo. Como vimos na seção 2, o impacto relativo de múltiplos do mínimo em relação a quem ganha exatamente um mínimo tende a ser mais expressivo neste segmento do que entre os empregados 
informais. Entretanto, a pobreza cai relativamente pouco neste estágio: a queda cumulativa passa de $2.53 \%$ para $3.33 \%$. O menor efeito de alívio da pobreza produzido na margem neste estágio em relação ao anterior pode ser creditado ao fato de o reajuste afetar predominantemente trabalhadores de maiores rendas tanto individualmente como em termos domiciliares per capita.

Ao se incorporar o efeito dos empregados sem carteira de trabalho que recebem múltiplos do mínimo na passagem do terceiro para o quarto estágio (barra MCFS), a queda de pobreza cumulativa passa de $3.33 \%$ para $5.42 \%$. Finalmente, no último estágio, MCFSE, ao incorporarmos os trabalhadores por conta própria e empregadores que recebem múltiplos do mínimo, a queda cumulativa de pobreza observada atinge $6.00 \%$.

\section{Considerações Finais}

De uma maneira geral, a análise de sensibilidade de queda da pobreza aponta para a importância de se incorporar na análise de diferentes efeitos do salário mínimo aqueles atuantes sobre os segmentos sem carteira, conta própria e aqueles derivados do uso do salário mínimo como numerário. Segundo as nossas simulações, o efeito aliviador de pobreza da visão tradicional do papel do mínimo, isto é, aquele incidente sobre os trabalhadores formais que ganham um salário mínimo (aí incluindo o efeito-arrasto), é menos de $42 \%$ do efeito total obtido quando se incorpora à análise todos os canais de atuação do mínimo mencionados acima. ${ }^{12}$

Entre os canais analisados, destacamos a importância de incorporarmos os efeitos exercidos pelo salário sobre os trabalhadores sem carteira de trabalho (que corresponde a cerca de $35 \%$ do efeito total), e, em menor medida, o efeito -numerário atuante sobre os empregados formais (que responde por $13.3 \%$ do efeito total) e o efeito do salário mínimo sobre os conta próprias e empregadores (em torno de $9.7 \%$ do total).

A incorporação de todos os efeitos do salário mínimo frente a um reajuste de $42.86 \%$ implicaria uma redução da proporção dos pobres de $6 \%$, supondo uma curva de demanda de trabalho totalmente inelástica e a ausência de impactos inflacionános.

Em segundo lugar, o valor de redução da proporção de pobres encontrado é ligeiramente superior àquele encontrado por Barros (1998) para três cenários alternativos, a saber: i) redução à metade da taxa de desemprego (para 4\%); ii) aumento da renda per capita de $3 \%$ anuais por dois anos consecutivos (com mantenção da taxa de desemprego); iii) aumento de escolaridade de toda a população brasileira de um ano de estudo, o que normalmente ocorre a cada década seguindo a tendência histórica brasileira. Coincidentemente, segundo o referido autor, a pobreza cairia cerca de $4.5 \%$ em cada um desses cenários traçados. Portanto, um nível inferior ao da redução de pobreza alcançado com o reajuste de $42.86 \%$ se

\footnotetext{
${ }^{12}$ A ordem segundo a qual os efeitos são computados pode afetar a sua participação relativa.
} 
incorporarmos todos efeitos do salário mínimo $(6 \%)$ e uma curva de demanda por trabalho totalmente inelástica.

Por último e mais importante, é óbvio que, além dos impactos sobre o nível de rendimento dos empregados considerados, aumentos do salário mínimo podem exercer impactos adversos sobre o emprego. No entanto, ainda não existem estimativas confiáveis para o Brasil da elasticidade emprego-salário para os trabalhadores sem carteira de trabalho e para os trabalhadores que recebem valores próximos ao salário mínimo (como, por exemplo, Card e Krueger [1995] encontram para os EUA). Nesse sentido, os nossos resultados sobre impactos do mínimo sobre a pobreza brasileira não podem ser levados a valor de face mas encarados como limites superiores. O ponto fundamental que o artigo pretende esclarecer é a necessidade da incorporação de efeitos do mínimo pouco discutidos na literatura à análise tanto empírica como teórica.

\section{CONCLUSÕES}

\section{Visão Geral}

O objetivo deste artigo foi subsidiar a formulação da política de salário mínimo no Brasil. Inicialmente, avaliamos o grau de efetividade da política de salário mínimo nacional sobre a determinação de salários nas diversas formas de inserção ocupacional dos trabalhadores brasileiros. A nossa técnica consistiu em mapear pontos de pressão/soluções de canto produzidas pela política de salário mínimo brasileira. Estes pontos captados individualmente foram posteriormente utilizados como mecanismo de focalização na simulação de efeitos de reajustes do salário mínimo sobre a renda familiar per capita e, em particular, sobre medidas de pobreza.

Vejamos as principais conclusões das diversas seções do artigo.

\section{Efetividade do Salário Mínimo nos Diversos Segmentos do Mercado de Trabalho}

O cálculo da efetividade do mínimo sobre a distribuição de salários se baseia diretamente no cálculo das soluções de canto impostas pelo salário mínimo à distribuição dos salários no Brasil. Os principais resultados desta parte são os seguintes:

Entre os ocupados remunerados brasileiros, $9 \%$ recebiam exatamente um salário mínimo em setembro de 1996;

O efeito-numerário, segundo o qual os indivíduos atrelam seus salários a determinados múltiplos do mínimo, constituiu um primeiro efeito do salário mínimo aqui considerado. Cerca de $6 \%$ do conjunto total de trabalhadores com carteira assinada remunerados ganhavam exatamente determinados múltiplos do salário mínimo vigente;

No conjunto dos funcionários públicos das três esferas de governo, a proporção de indivíduos com salários idênticos ao mínimo é similar àquela observada 
entre os trabalhadores com carteira assinada: $8 \%$. Já o uso do salário mínimo como numerário se revelou menos proeminente entre os funcionários públicos: $2 \%$.

Surpreendentemente, a legislação do salário mínimo é mais efetiva (binding) no segmento assalariado ilegal do mercado de trabalho brasileiro do que no segmento legal: $15 \%$ contra $8 \%$, respectivamente, recebiam exatamente um mínimo.

\section{Simulações dos Efeitos do Salário Mínimo sobre a Pobreza}

O objetivo desta seção foi avaliar o impacto de reajustes do salário mínimo sobre os indicadores de pobreza brasileiros. O exercício básico consistiu em simular o efeito de um determinado reajuste real do salário mínimo sobre a renda dos indivíduos de diferentes segmentos do mercado de trabalho para os quais a política de salário mínimo é efetiva (binding), supondo um efeito nulo sobre o nível de emprego. A identificação dos indivíduos afetados pelo mínimo seguiu a metodologia desenvolvida na seção 2. Posteriormente, agregam-se no nível familiar as rendas do trabalho simuladas individualmente e calculam-se indicadores de pobreza.

A incorporação de todos os efeitos do salário mínimo aqui considerados frente a um reajuste de $42.86 \%$ implicaria numa redução da proporção dos pobres de $6 \%$. As simulações apontam para a importância de se incorporar na análise efeitos informais do salário mínimo, como aqueles atuantes sobre os segmentos sem carteira, conta própria e aqueles derivados do uso do salário mínimo como numerário. O efeito aliviador de pobreza da visão tradicional do papel do mínimo, isto é, aquele incidente sobre os empregados formais que ganham um salário mínimo, corresponde a menos de $42 \%$ do efeito total obtido.

Dentre os canais de influência do mínimo, destacamos a importância de incorporarmos os efeitos exercidos pelo salário sobre os trabalhadores sem carteira de trabalho (que corresponde a cerca de $35 \%$ do efeito total), e, em menor medida, o efeito numerário atuante sobre os empregados formais (que responde por $13,3 \%$ ) e o efeito do salário mínimo sobre os conta próprias e empregadores (em torno de $9,7 \%$ ).

É óbvio que, além dos impactos sobre o nível de rendimento dos empregados considerados, os aumentos do salário mínimo devem exercer impactos adversos sobre o emprego. No entanto, ainda não existem estimativas confiáveis para o Brasil da elasticidade emprego-salário para os trabalhadores sem carteira de trabalho e para os trabalhadores que recebem valores próximos ao mínimo. Neste sentido, os nossos resultados sobre impactos do mínimo sobre a pobreza brasileira não podem ser levados a valor de face, mas encarados como limites superiores. O ponto fundamental que o artigo pretende esclarecer é a necessidade da incorporação de diversos reflexos do "efeito-farol" produzido pelo mínimo à análise. 


\section{REFERÊNCIAS}

AMADEO, E. e NERI M., "Política Macroeconômica y Pobreza en Brazil”, em Política Macroeconomica y Pobreza en America Latina y e/ Caribe, E. Ganuza e L. Taylor (orgs.), México: Fondo del Cultura, 1998.

BARROS R., "Estudo Dissocia Desemprego e Pobreza", in Gazeta Mercantil, São Paulo: 20 de maio de 1998.

CARD, D. e KRUEGER, A., Myth and Measurement: The New Economics of the Minimum Wage, Princeton: Princeton University Press, 1995.

GRAMLICH, Edward M. "Impact of Minimum Wages on Other Wages, Employment and Family ln. comes" in Brookings Papers on Economic Activity, Arthur M. Okun e George L. Perry (orgs.), vol. 2, Washington DC: Brookings Institution, 1976.

NERI, M., “O Reajuste do Salário Mínimo de Maio de 1995”, em Anais da Sociedade Brasileira de Econometria, Recife, 1997.

RAMOS, L. e REIS, J. “Minimum Wage, Income Distribution and Poverty in Brazil”, Texto para Discussão n 359, IPEA, 1994.

SOUZA, P.R. e BALTAR, P. "The Minimum Wage and Wage Rates in Brazil, Brazilian Economic Studies, n ${ }^{\circ} 7,1982-3$. 